\title{
Phenotypic features of Helicina variabilis (Gastropoda: Neritimorpha) from Minas Gerais, Brazil
}

\author{
Luiz Ricardo L. Simone ${ }^{1}$ \\ 1 Universidade de São Paulo (USP), Museu de Zoologia (MZUSP). São Paulo, SP, Brasil. ORCID: 0000-0002-1397-9823. E-mail: Irsimone@usp.br
}

\begin{abstract}
Helicina variabilis Wagner, 1827 (Neritimorpha, Helicinidae) is redescribed based on a sample collected in Nanuque, northern Minas Gerais, Brazil. The species description, previously based only on the shell, is expanded to the phenotypic features. The study revealed absorption of the internal shell whorls; a diaphragm muscle connected to the floor of the pallial cavity; a monoaulic pallial oviduct, with the female genital aperture inside the anal aperture, and the lack of a seminal receptacle and provaginal sac; and the pleural ganglia of the nerve ring connected with each other. The significance of these findings is discussed in the light of current taxonomic and phylogenetic knowledge.
\end{abstract}

Key-Words. Atlantic Rainforest; Helicinidae; Anatomy; Morphology; Phenotype.

\section{INTRODUCTION}

With the main goal of filling a gap in knowledge of neritimorph phenotypic features, a more complete anatomical description of Helicina variabilis Wagner, 1827 is provided herein. Specimens of this species were collected during an expedition by the naturalist and conchologist José Coltro Jr. and his team to the region of Nanuque in northern Minas Gerais state, which recovered many land snails, most of them reported by Simone \& Salvador (2016). This is another example of how much remains to be discovered in a region of Brazil that is historically the most explored and exploited, and in which the natural areas, mainly remnants of the Atlantic Rainforest, are highly threatened, lacking information that allows their preservation.

Knowledge of the helicinids as a whole is slight, although it is a relatively speciose group (up to 750 species; Richling \& Glaubrecht, 2008), particularly in the Americas (Richling, 2004, 2014). Anatomical features in particular have been very useful in comparative analyses, such as taxonomy and phylogeny, at all levels, from closely related species (e.g., Richling, 2009; Richling \& Bouchet, 2013) to wider systematic studies, specifically in helicinids (Richling, 2004) and in gastropods in general (Simone, 2011). However, anatomical features have been barely used in neritimorphs. As part of a larger project on phenotypic features and phylogeny of the Neritimorpha (= Neritopsina), Helicina variabilis was selected as one of the terrestrial representatives of the group, as it appears to be a typical member of the family. Eventually, the estimated systematic relationships based on comparative anatomical information will be compared to those inferred using molecular approaches (e.g., Uribe et al., 2016).

The Helicinidae constitute a terrestrial branch of the Neritimorpha (Richling \& Glaubrecht, 2008), a taxon with $\sim 2,000$ species in four superfamilies, Neritopsoidea, Hydrocenoidea, Helicinoidea (which includes the family Helicinidae), and Neritoidea (Uribe et al., 2016), most of the species in the last two taxa. The helicinids are easily distinguished from the more common Pulmonata snails in having a well-developed, normally calcareous operculum, and the eyes placed at the base of a single pair of cephalic tentacles. Their shells are discoid to globose, with a suture plane, sometimes carinate at the periphery, and an umbilicus absent. These features easily distinguish them from the other operculate land snails belonging to Cyclophoroidea, which is basal to the Caenogastropoda (Simone, 2011).

Focusing on the Caenogastropoda, Simone (2011) included only a few neritimorph species as outgroups; none of these were terrestrial, a gap filled by the present study. As in most branches of Mollusca, the anatomical features of helicinids have been considered uniform and of limited use in comparative analyses (e.g., Bourne, 1911; Boss \& Jacobson, 1974). For this reason, most studies of helicinid systematics have focused on the shell and radula (e.g., Wagner, 1907-1911; Baker, 1922, 1923). Only more recently have some anatomical characters, primarily from the reproductive system, been used as an additional tool to resolve the systematics of the group (e.g., Richling, 2004, 2009), mainly focused on the reproductive system. 
The helicinids share some important neritimorph features, such as the absorption of the inner whorls of the shell, producing a sac-like, coil-less visceral mass (Bourne, 1911). The type of radula, the shape of the columellar muscles, and the calcareous operculum are additional synapomorphies (Simone, 2011). On the other hand, using the study of Helicina variabilis as an example, together with literature data, it is possible to suggest some features that distinguish the helicinids at least from the marine Neritidae, as discussed below.

\section{MATERIAL AND METHODS}

The list of material examined follows the species description. The specimens studied were collected in the vicinity of the city of Nanuque $\left(\sim 17^{\circ} 51^{\prime} \mathrm{S} 40^{\circ} 23^{\prime} \mathrm{W}, \sim 120 \mathrm{~m}\right.$ elevation) in northern Minas Gerais state, very close to the border with the states of Bahia and Espírito Santo. The locality is a tiny fragment of Atlantic Rainforest close to the Mucuri River, surrounded by tomato fields and thus highly subject to anthropogenic impacts and degradation. See Simone \& Salvador (2016) for more details.

The snails were collected alive and preserved in $70 \%$ ethanol. For dissection, each specimen was extracted from its shell through an artificial window made in the penultimate whorl with a metal file. The specimens were dissected by standard techniques, under a stereomicroscope, with the specimen immersed in ethanol. Digital photographs were obtained for most dissection steps, as well as drawings with the aid of a camera lucida. The radulae were mounted on stubs, coated with a gold-palladium alloy, and examined by scanning electron microscopy (SEM) in the Laboratório de Microscopia Eletrônica of MZSP.

Anatomical abbreviations: aa, anterior aorta; ag, albumen gland; an, anus; ap, genital aperture; ar, adrectal sinus; au, auricle; bc, bursa copulatrix; bg, buccal ganglia; cc, cerebral commissure; ce, cerebral ganglion; cg, capsule gland; $\mathbf{c l}$, right columellar muscle; $\mathbf{c r}$, left columellar muscle; cv, pulmonary (efferent) vein; cy, statocyst; dd, duct to digestive gland; di, diaphragm or pallial floor; $\mathbf{d m}$, diaphragm muscle; dv, posterior diverticulum of albumen gland; ec, esophageal crop surrounding odontophore; ep, esophageal pouch; es, esophagus; ey, eye; $\mathbf{f p}$, female pore; fs, foot sole; ft, foot; go, gonad; gp, pedal ganglion; il, intestinal haemocoelic loop; in, intestine; ki, kidney chamber; kl, kidney lobe; m1-m13, extrinsic and intrinsic odontophore muscles; $\mathbf{m b}$, mantle border; mj, jaw and peribuccal muscles; mo, mouth; $\mathbf{m t}$, mantle; ne, nephrostome; nr, nerve ring; oa, opercular pad; oc, odontophore cartilage; od, odontophore; om, ommatophore; op, calcareous operculum; ov, pallial oviduct; oy, ovary; pc, pericardium; pg, pedal gland; pl, pleural ganglion; po, posterior odontophore cartilage; pu, pulmonary cavity; ra, radula; rn, radular nucleus; rs, radular sac; rt, rectum; sc, subradular cartilage; sn, snout; st, stomach; sy, statocyst; te, cephalic tentacle; tg, integument; ve, ventricle; vo, visceral oviduct.

\section{Systematics}

Helicina variabilis Wagner, 1827

(Figs. 1-35)

Helicina variabilis Wagner, 1827: 25 (pl. 16, figs. 3-5) [see authority designation in Cowie et al., 2004]; Wagner, 1906: 226 (pl. 13, figs. 2a-c.); Salgado \& Coelho, 2003: 152 (pl. 1, fig. 1); Simone, 2006: 41 (fig. 32); Simone \& Salvador, 2016: 10, 11, 29 (figs. 84-89).

Type locality: Pará state, Brazil.

Material analyzed: BRAZIL. Minas Gerais: Nanuque: MZSP 106171 (1 specimen), 106172 (4 specimens), 106173 (1 shell). Bahia: NE Ilhéus; MZSP 128202 ( 2000 shells) (Femorale team col. xii/1994).

\section{Description}

Shell (Figs. 1-10): diameter $\sim 12 \mathrm{~mm}$, lenticular; diameter $\sim 5 / 4$ shell length. Base color white, with broad spiral band running along median upper portion of whorls; varying in thickness, sometimes covering all of upper portion of whorls, and changing from orange to light brown or reddish purple; second, narrow colored band (of same color as other band and also varying in thickness, although less so) sometimes present on lower surface of whorls, closer to median portion. Both bands stopping few millimeters before reaching peristome. Peristome white. Spire angle $\sim 90^{\circ}$. Protoconch of 1.5 whorls, acuminate, first 0.75 whorl smooth, rest sculptured by axial parallel sinuous striae; transition to teleoconch distinct. Teleoconch sculptured with weak axial parallel sinuous striae and with stronger spiral parallel striae. Whorl profiles slightly convex. Suture well marked. Very weak carina on body whorl. Aperture medium-sized, prosocline, triangular, about as broad as high; 2/3 shell length, $\sim 3 / 5$ shell width. Peristome reflected, with shallow furrow on median upper portion (following colored band) and slight angle at junction of basal and columellar regions. Body whorl $~ 3 / 4$ shell length. Umbilicus imperforate. Internal visceral cavity ample, separated from head-foot cavity by thin septum (Figs. 9-10); occupying $\sim 2 / 3$ of shell volume; intra-sutural fold (vestigial internal coiling) low, but visible (Fig. 10).

Head-foot (Figs. 8, 30-22): Color of exposed regions brown; snout pale beige (Fig. 8). Length $\sim 3 / 4$ whorl when retracted. Head protruded, occupying $\sim 1 / 2$ foot width. Tentacles stubby, simple, ca. four times longer than wide; tip blunt (Figs. 20, 26: te). Ommatophore (om) $\sim 1 / 3$ tentacle length, tip rounded; located close to outer side of tentacle base. Eye (ey) located on ommatophore tip. Foot simple, thick, subtriangular (Figs. 20-22: ft); anterior edge bilabiate, aperture of pedal glands median, relatively deep (Fig. 20: pg). Distance between anterior edge of foot and snout base $\sim 1 / 10$ whorl. Both columellar muscles diverging towards posterior portion of body, very thick, gradually tapering 
posteriorly; originating from both sides of pseudo-columellar region; left columellar muscle (Figs. 20-21: cr) $\sim 3 / 4$ shorter and more inclined than right columellar muscle (cl). Opercular pad simple (Fig. 22: oa), slightly elliptical. Haemocoel ca. three times longer than wide, slightly narrowing posteriorly; occupying $\sim 1 / 3$ of headfoot volume (Fig. 24).

Operculum (Figs. 11-13): Hard, translucent, occupying entire aperture. Extending 20\% beyond lateral sides of foot (Fig. 21: op). Color pale brown, scantly calcified; relatively thin (Fig. 13). Nucleus barely visible, located in middle of inferior half (Fig. 11). Outer surface smooth, weakly undulating concentrically. Edges somewhat flexiclaudent. Inner surface smooth, glossy; scar elliptical, close to inner margin, occupying $\sim 40 \%$ of inner surface (Fig. 12).

Pallial cavity (Figs. 23-25): Length $\sim 1 / 2$ whorl (Fig. 14), relatively narrow. Mantle border thin, bifolded (Fig. 23: $\mathrm{mb}$ ). Lung venation relatively weak and barely visible (Fig. 23: pu), except for collar vessel running parallel to mantle border, and large pulmonary vein (cv) running along left edge of cavity to pericardium. No vestige of gill or osphradium. Rectum and gonoducts occupying $\sim 1 / 3$ of right pallial volume, along its entire length (Fig. 23: rt, ov). Anus located close to right side of mantle border (an). Adrectal sinus (Figs. 23, 25: ar) narrow, running parallel to left side of rectum, inserting in anterior corner of kidney.

Visceral mass (Figs. 14, 25): Single compact discoid mass as inner mold of visceral cavity of shell (vm) (Figs. 9-10). Gonad (go) occupying 70\% of inner visceral volume, granular, cream-colored. Stomach and digestive gland occupying remaining $\sim 30 \%$ of visceral volume, located anteriorly and ventrally. Diaphragm muscle narrow (Figs. 14, 25, 26: dm), originating from small area close to origin of left columellar muscle; running ventrally and posteriorly flanking ventral surface of visceral mass; tapering to its insertion in posterior region of pallial cavity floor.

Reno-pericardial system (Fig. 25): Located as anterior structures of visceral mass (Fig. 23: pc), both combined occupying $\sim 15 \%$ of visceral volume. Kidney narrow, oblique, mostly hollow (ki); occupying $\sim 1 / 3$ of reno-pericardial volume. Renal lobe on anterior surface (kl), small, as pair of parallel glandular folds bearing successive transverse folds. Nephrostome (ne) as simple, transverse slit located in posterior right corner of pallial cavity. Pericardium simple (pc), located on posterior region of pallial roof. Auricle (au) wide, thin-walled, situated anterior-right; with connections with pulmonary vein (cv) anterior-left, with kidney middle-right, and also posteriorly. Ventricle (ve) smaller and thicker-walled, turned to left and slightly posterior. Posterior aorta very small, splaying in visceral mass. Anterior aorta four to five times wider than posterior aorta, running anteriorly along haemocoel to buccal mass (Figs. 27-28: aa).
Digestive system (Figs. 24-31): Mouth subtriangular, located at median level of posterior region of snout central surface (Fig. 24: mo). Oral tube short, thin-walled (Fig. 27: mo); no jaw plates detectable, muscular wall relatively thin (Fig. 28: mj). Buccal mass occupying $\sim 1 / 3$ of haemocoel volume (Fig. 24); odontophore (od) ventral, almost entirely surrounded by esophageal crop (Figs. 24, 27, 28: ec), except for its posterior surface. Esophageal crop (ec) simple, inner surface smooth, velvet-like. Pair of esophageal pouches (Figs. 24, 27, 28: ep) as elongated diverticula, almost as long as buccal mass; right pouch ca. three times longer than wide; left pouch ca. four times longer than wide (Fig. 28: ep); posterior end rounded; running parallel to esophagus; inner surface simple, similar to esophageal crop. Anterior aorta inserting in region between odontophore and esophageal origin (Fig. 28: aa). Odontophore ca. twice longer than wide, occupying $\sim 1 / 2$ of buccal mass volume.

Odontophore muscles (Figs. 29-31): m1, several small pairs of jugal muscles connecting structures of haemocoel with adjacent inner surface of haemocoel, more concentrated close to oral tube; $\mathbf{m} \mathbf{2}$, pair of retractor muscles of buccal mass, originating from inner lateral surface of haemocoel, just posterior to snout, running short distance towards anterior and medial, inserting in latero-ventral edge of anterior cartilages, between their middle and anterior thirds (Fig. 30: m2); m3, two pairs of dorsal protractor muscles of odontophore, originating from antero-ventral surface of esophageal crop, running posterior-ventrally, inserting in anterior-ventral edge of posterior cartilages (Fig. 31: m3); $\mathbf{m 4}$, pair of thick dorsal tensor muscles of radula; originating from surrounding posterior and lateral edges of posterior cartilages (po) and postero-ventral edge of anterior cartilages (oc) (Fig. 30: m4), running short distance, narrowing, inserting along radular sac on posterior half of odontophore (Fig. 30: ir); $\mathbf{m 5}$, auxiliary dorsal tensor muscle of radula absent or indistinct, as part of $\mathrm{m} 4 ; \mathbf{m} \mathbf{6}$, horizontal muscle connecting both anterior odontophore cartilages (oc) with each other, along $\sim 2 / 3$ of their ventro-medial edge (Figs. 30-31: m6), initiating $\sim 1 / 10$ of anterior cartilage length posterior to their anterior end; $\mathbf{m 8}$, pair of approximator muscles of cartilages, connecting anterior surface of posterior cartilages (po) with ventro-posterior surfaces of anterior cartilages (oc) (Fig. 31: m8), relatively thick, covering $\sim 1 / 2$ of anterior cartilages outer surface; $\mathbf{m} \mathbf{1 0}$, pair of wide ventral protractor muscles of odontophore, originating from ventral region of snout close to buccal tube origin, running along almost entire odontophore length, covering its ventro-lateral surface (Fig. 29: m10), inserting in latero-ventral edge of posterior cartilages (Figs. 29, 31: $\mathrm{m} 10$ ), close to $\mathrm{m} 3$ insertions; $\mathbf{m 1 1}$, pair of narrow ventral tensor muscles of radula, originating from median edge of posterior cartilages, running anteriorly close to median line, flanking ventral edge of anterior cartilages (Fig. 31: $\mathrm{m} 11$ ), inserting in terminal edge of radular ribbon. Non-muscular odontophore structures: oc, pair of anterior odontophore cartilages, each one ca. four times longer than wide, slightly flattened, anterior 
tip bluntly pointed, weakly curved inwards, posterior edge almost straight, articulating with posterior cartilages (Fig. 30: oc); po, pair of posterior odontophore cartilages, subspherical, slightly flattened, located just posterior to anterior cartilages, 1/5 their length; sc, subradular cartilage, thin, transparent, running along entire ventral surface of radular ribbon (connecting radular teeth), expanding ca. twice radular ribbon width in oral cavity (Fig. 28: sc), protecting subradular membrane.

Radular teeth (Figs. 15-19): rachidian tooth slightly longer than wide, occupying $1 / 10$ of radula width, cutting edge strongly curved inwards, slightly wider than base, composed of transverse secondary folds, no cusps; four pairs of lateral teeth (Figs. 16, 18), pair of inner lateral teeth sigmoid, $c a$. three times narrower than rachidian, pair of small terminal cusps on tip, sometimes 1-2 more cusps along internal edge, turned outwards; pair of second lateral teeth similar to inner lateral, but ca. twice wider, with 5-7 small cusps on cutting edge, medial cusps slightly smaller than lateral cusps; pair of third lateral teeth similar to inner lateral, but positioned turned inwards; pair of outer lateral teeth large, each occupying $\sim 20 \%$ of radular width, tooth base wide, triangular, ca. twice rachidian length and width, outer edge reinforced, thicker at base, terminal rod also triangular and turned inwards, but narrower than base, 10-12 cusps on outer edge, turned inwards, middle cusps slightly larger than terminal cusps; lateral teeth forming chevron, second and third teeth lying at midlevel of two successive rachidians; $c a .50$ pairs of marginal teeth arranged obliquely as continuation of outer lateral tooth; all marginal teeth similarly shaped, but gradually decreasing in size laterally. More internal marginal teeth $\sim 10$ times longer than wide, base flattened, tip curved inwards, with 4 terminal cusps, middle cusps larger than distal and proximal cusps (Figs. 17, 18); 3-4 pairs of more marginal teeth differently shaped than remaining more medial marginal teeth, claviform, flattened, tip rounded, simple, lacking cusps (Figs. 18, 19).

Esophagus simple, relatively wide; inner surface smooth, lacking folds (Figs. 27-28: es); running along $\sim 1 / 2$ whorl to stomach insertion (Fig. 26: es). Stomach as wide blind sac, located in central region of visceral sac, occupying $\sim 1 / 5$ visceral sac volume (Fig. 26: st); inner surface simple, lacking special folds or sorting areas, pair of ducts to digestive gland (Fig. 26: dd) located close to each other, in anterior region of esophageal insertion in stomach. Border between stomach and intestine indistinct. Intestine formed by gradual narrowing of stomach, with two loops (Fig. 26: in), anterior loop into haemocoel, reaching left-posterior region of buccal mass (Fig. 26); next, loop running along ventral visceral surface, crossing kidney, reaching pallial cavity as rectum (Fig. 23: in, rt). Rectum relatively wide ( $\sim / 5$ of pallial-cavity width), running along right side of pallial cavity. Anus wide, located close to right side of mantle border (Figs. 23, 35: an).

Genital system: Male: No males examined. Female (Figs. 23, 24-35): Ovary described above (Fig. 14: go).
Visceral oviduct (vo) very narrow, running along columellar surface of visceral mass to right side of posterior pallial cavity end (Figs. 23, 25: vo). Pallial oviduct (ov) wide, almost as long as pallial cavity; running along pallial cavity right side, covering rectum ventrally (Fig. 23: ov). Posterior region of pallial oviduct as abrupt expansion of visceral oviduct (Figs. 23, 34), performing short zigzag ( 1/8 of entire pallial-oviduct length), albumen gland (ag) as initial paler region. Seminal receptacle absent. Bursa copulatrix (Fig. 34: bc) as three branched diverticula, located in postero-ventral region of albumen gland; its duct placed anteriorly, between albumen and capsule glands. Posterior oviduct diverticulum (Fig. 34: dv) simple, located in opposed side from bursa, filled by gland. Capsule gland (cg) occupying most of pallial oviduct, walls thick, glandular (Figs. 34, 35: cg), pale beige, somewhat convolute (Fig. 23: ov). Genital atrium short, located just anterior to capsule gland. Female aperture as elongated, simple papilla (Fig. 35: fp), preceded by thin walls; papilla located inside wide anal aperture (Figs. 23, 35).

Central nervous system (Figs. 32, 33): Nerve ring located in ventral region of snout base, occupying $\sim 1 / 20$ of haemocoel volume (Fig. 24: nr), surrounding oral tube close to its posterior region (Fig. 27: nr). Pair of cerebral ganglia (ce), each ganglion occupying $\sim 20 \%$ of nervering volume, relatively spherical; cerebral commissure slightly longer than each ganglion length. Pair of pedal ganglia (gp) about as large as cerebral ganglia, very closely connected with each other; each ganglion subspherical, tapering to large anterior pedal nerve. Statocyst (cy) $\sim 1 / 5$ pedal ganglion volume, bearing several statoconia; located on ventral side of middle region of each pedal ganglion. Pair of pleural ganglia ( $p l$ ) located close to pedal ganglia, $\sim 1 / 2$ of their size; both widely connected on median side. Cerebro-pleural and cerebro-pedal connectives relatively symmetrical, about as long as cerebral commissure; right pair somewhat more widely separated from each other than left pair.

Mean measurements (in $\mathbf{m m} ; \mathbf{n}=\mathbf{6}$ ): 4.5 to 5 whorls; $H=9.7 \pm 0.7(\max 10.7 ; \min 8.7) ; \mathrm{D}=12.4 \pm 0.6(\max 13.2 ;$ $\min 11.6) ; S=4.0 \pm 0.6(\max 4.5 ; \min 3.1) ; S^{\prime}=2.3 \pm 0.3$ $(\max 2.9 ; \min 2.0) ; \mathrm{h}=7.1 \pm 0.4(\max 7.7 ; \min 6.7)$; $\mathrm{d}=7.3 \pm 0.4(\max 7.9 ; \min 6.7)$.

\section{DISCUSSION}

The previously known distribution of $H$. variabilis includes the Brazilian states of Paraíba, Bahia, Espírito Santo, and Rio de Janeiro (Wagner, 1827; Simone, 2006). The present record slightly extends the species distribution to NE Minas Gerais state.

As the epithet suggests, this species is known for its wide variability in the shell color pattern, from completely white to almost completely brown (Figs. 5-7), and commonly shows a banded pattern (Figs. 1-4), easily seen in the numerous specimens in sample MZSP 128202. Despite this variability, $H$. variabilis can be distinguished 
from its Brazilian congeners (Simone, 2006) in having a relatively tall shell, a rather weak peripheral carina, the peristome slightly displaced downwards, and the presence of spiral striae with irregular interspaces.

Helicina variabilis shows the normal anatomical pattern of the family (Bourne, 1911; Richling, 2004), with the single main monoaulic pallial oviduct characteristic of the genus Helicina, in which the single aperture is anterior. Also, although it apparently is a common helicinid feature, the female genital aperture inside the anal aperture is noteworthy, but not exclusive, as Alcadia hollandi (C.B. Adams, 1849) also has this feature (Bourne, 1911: fig. 25). Another remarkable character is the connection of the pleural ganglia with each other. Normally this pair

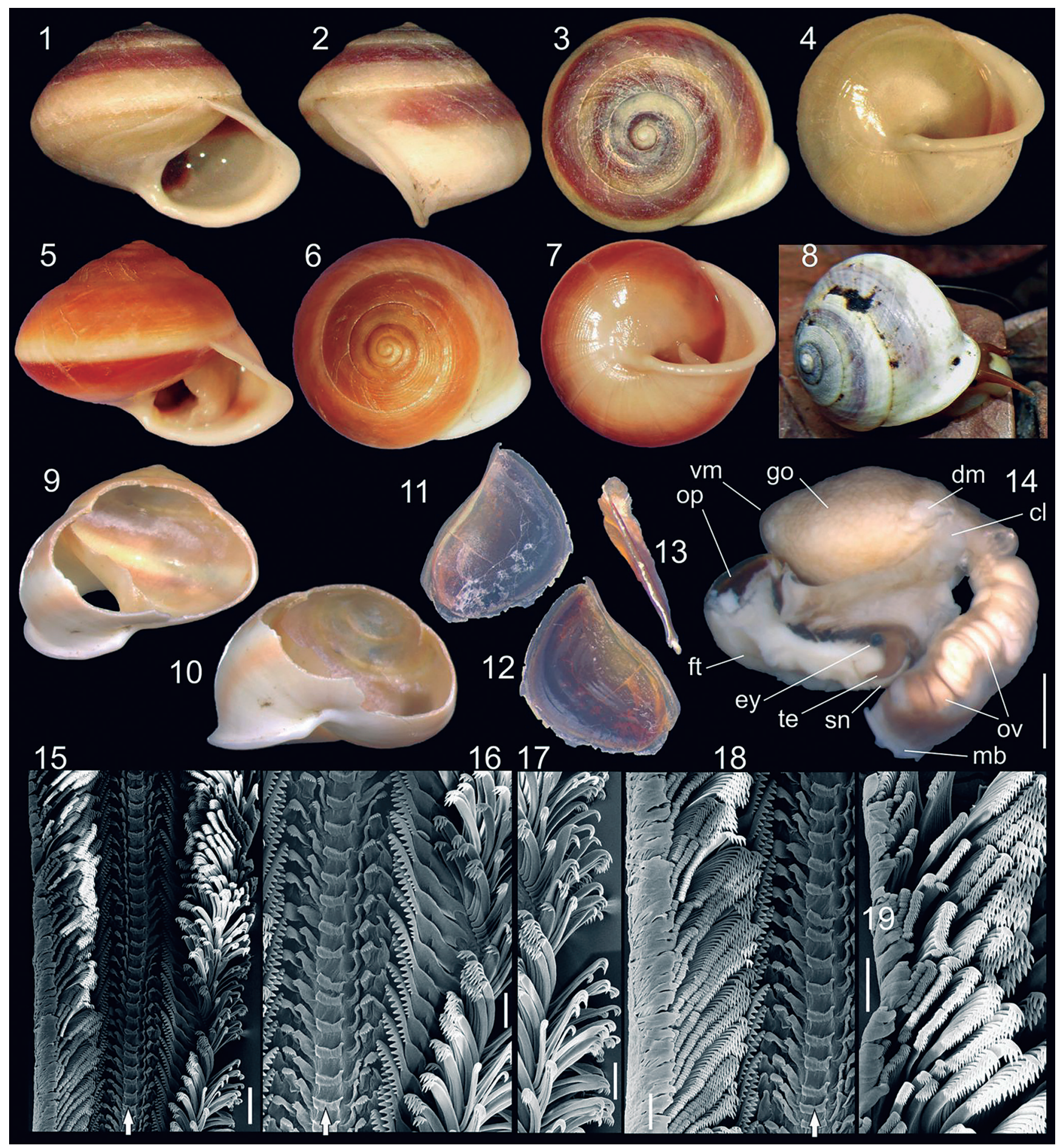

Figures 1-19. Helicina variabilis. (1-14) phenotypic features; (1) specimen \#1 (MZSP 106171; D = $12.9 \mathrm{~mm}$ ), frontal view. (2) same, lateral view. (3) same, apical view. (4) same, umbilical view. (5) specimen \#2 (MZSP 106172; $D=12.5 \mathrm{~mm}$ ), frontal view. (6) same, apical view. (7) same, umbilical view. (8) living specimen (MZSP 106172) $(D=11.8 \mathrm{~mm})$. (9) shell, dorsal view, with part of shell wall removed in order to expose visceral cavity. (10) same, oblique umbilical view. (11) operculum, outer view (width $=5.8 \mathrm{~mm}$ ). (12) same, inner view. (13) same, lateral view. (14) specimen removed from shell, mostly frontal view, pallial cavity partially removed and deflected downwards (scale $=2 \mathrm{~mm}$ ). (15-19) radulae in SEM, arrow showing rachidian column; (15) wide view (scale $=100 \mu \mathrm{m})$. (16) detail of central region $($ scale $=50 \mu \mathrm{m})$. (17) detail of marginal region $(s c a l e=50 \mu \mathrm{m}) .(18)$ central and marginal region (scale $=50 \mu \mathrm{m}) .(19)$ detail of marginal region $(\mathrm{scale}=50 \mu \mathrm{m})$. 
of central ganglia does not have a commissure, but this is not the case for $\mathrm{H}$. variabilis (Figs. 32, 33: pl); nevertheless, further studies are necessary to establish if the pleural ganglia of $H$. variabilis is really homologous to the pleural ganglia of other gastropods. A similar arrangement of the nerve ring, also with the two pleural ganglia connected, has been reported at least in A. hollandi (Bourne, 1911: fig. 44) as well as in the neritid Neritina zebra (Bruguière, 1792) (Barroso et al., 2012: fig. 30). This feature may be a neritimorph synapomorphy.

In the genital system, the main exclusive character of $H$. variabilis is the lack of a seminal receptacle (re-

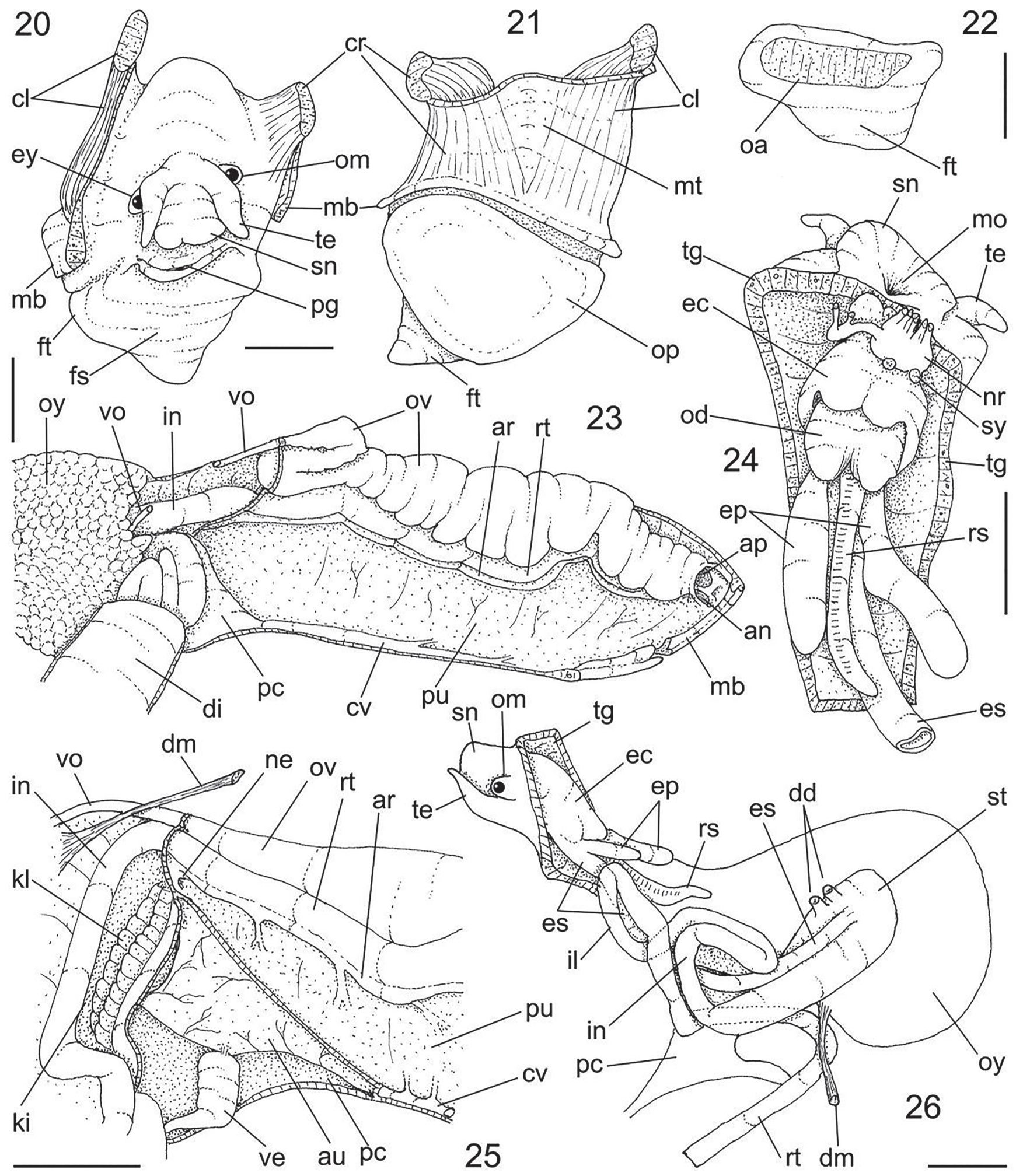

Figures 20-26. Helicina variabilis. anatomy; (20) head-foot, anterior view. (21) same, posterior view. (22) detail of posterior region of foot, dorsal view. (23) pallial cavity roof and adjacent region of visceral mass and head-foot, ventral-inner view, artificially sectioned in middle of mantle border. (24) head and haemocoel, ventral view, foot and columellar muscles removed. (25) posterior end of pallial cavity and adjacent region of visceral mass, ventral view, ventral wall of pericardium removed. (26) digestive tubes as in situ, left view, topology of some adjacent structures also shown. Scales $=2 \mathrm{~mm}$. 
ceptaculum seminis - Richling, 2004: fig. 4B), as well as the lack of a provaginal sac and duct (e.g., Richling \& Boucher, 2013: fig. 20), and only a well-developed bursa copulatrix is present. The bursa with branched profile appears to be a common feature of the helicinids (Baker, 1926). The characteristics of the branches can be used as a taxonomic feature. The bursa of $\mathrm{H}$. variabilis has three main branches, each branch subdividing distally (Fig. 34: bc), which appears to be an exclusive character.
The kidney of $H$. variabilis is relatively simple for a terrestrial invertebrate. It is mostly hollow, possessing a small renal lobe (Fig. 25: kl). The auricle, on the other hand, is huge (Fig. 25: au), and is triangular with vertices at the right connection with the kidney, the connection with the remnant of the ctenidial vein (cv), and with the ventricle (ve). Another noteworthy character is the diaphragm muscle (Figs. 25, 26: dm), which may help in breathing movements, as it is absent in the aquatic forms. A similar muscle is present in the non-related

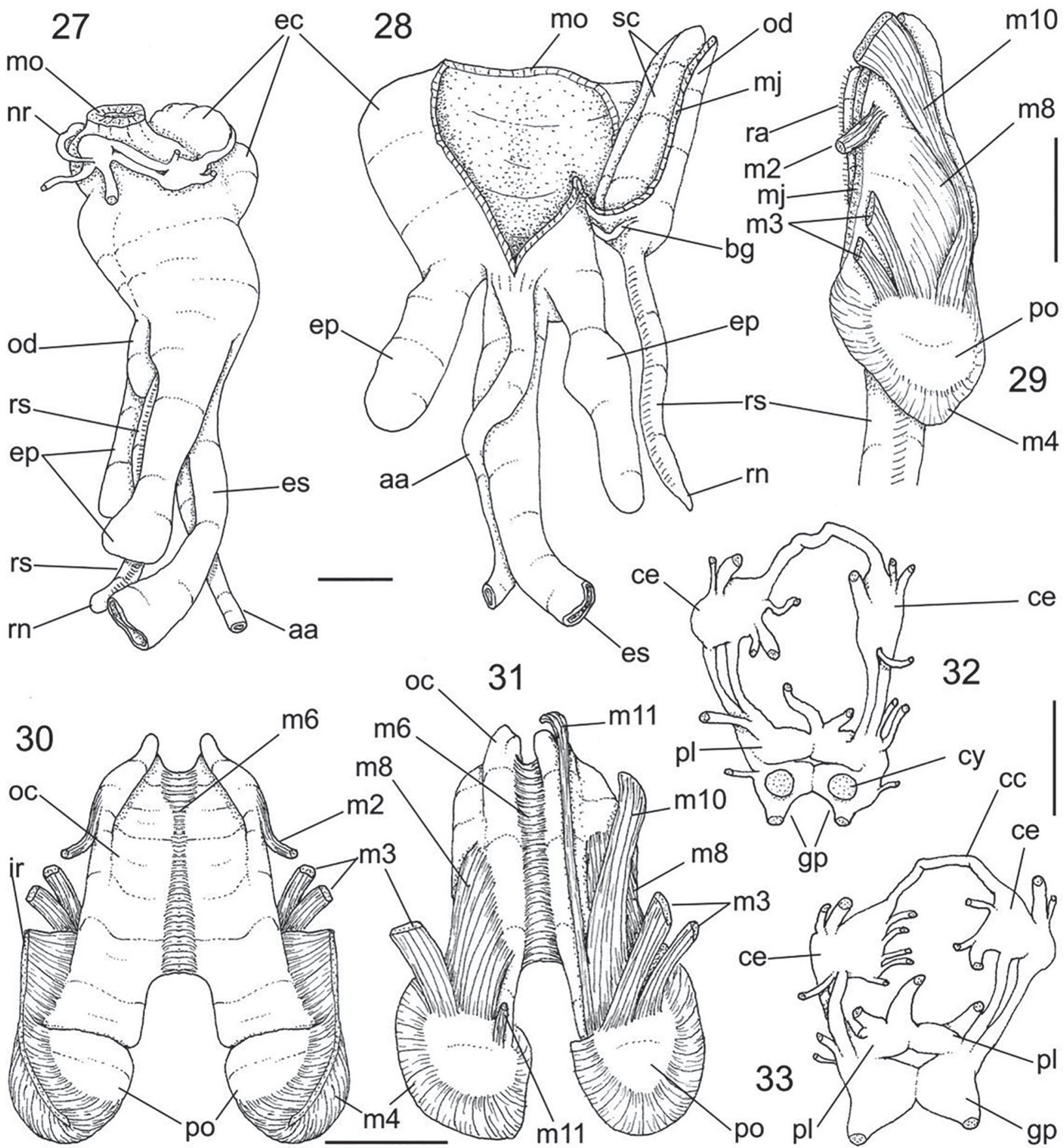

Figures 27-33. Helicina variabilis. anatomy; (27) foregut, left view, topology of nerve ring also shown. (28) same, ventral view, odontophore partially removed and deflected. (29) odontophore, left view. (30) same, dorsal view, superficial layer of membrane and muscles removed, both anterior cartilages deflected. (31) same, ventral view, part of right extrinsic muscles removed. (32) nerve ring, ventral view. (33) same, dorsal view. Scales $=1 \mathrm{~mm}$. 


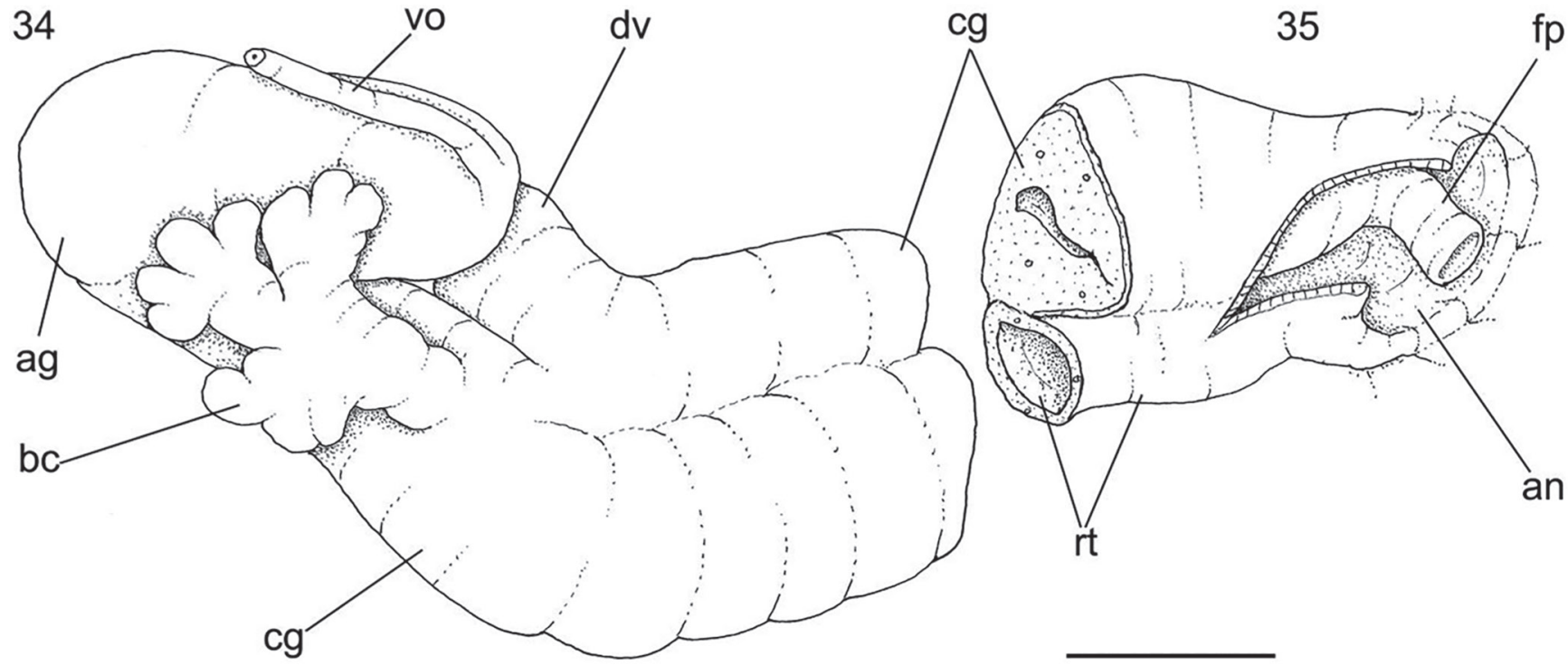

Figures 34-35. Helicina variabilis, portions of pallial oviduct, ventral view; (34) detail of posterior region. (35) detail of anterior region, anus edge artificially opened longitudinally. Scales $=1 \mathrm{~mm}$.

Ampullariidae (basal Caenogastropoda) (Simone, 2004, as gastric muscle), another air-breathing group.

With respect to the odontophore, $H$. variabilis, as well as other helicinids (Bourne, 1911: figs. 5-7), has some similarity with that of the neritid N. zebra (Barroso et al., 2012: figs. 25-29), with an inner arrangement in two pairs of cartilages, one anterior and one posterior. However, the helicinids so far known have the horizontal muscle (m6) single, not divided into two components (Figs. 30, 31). The pair of odontophore protractors $(\mathrm{m} 10)$ is inserted far posteriorly (Fig. 29) in both species, separating them from related taxa (Simone, 2011); however, that of $H$. variabilis is longer and slender. The pair of retractor odontophore muscles (Figs. 29, 30: $\mathrm{m} 2$ ) is simple in $\mathrm{H}$. variabilis, but is highly branched in N. zebra ("ml" Barroso et al., 2012). Details of the pairs $m 3$ are different from those of $N$. zebra, but these $\mathrm{m} 3$ muscles, as well as the jugal muscles $\mathrm{m} 1$, normally are the most variable, even in closely related species. The stomach of $H$. variabilis has a pair of ducts to the digestive gland, located close to each other (Fig. 26: dd); the other known helicinids usually have these ducts on opposite sides of the stomach (e.g., Bourne, 1911: figs. 10-15), but the remaining digestive features appear similar, including the well-developed pair of esophageal pouches (Fig. 24: ep).

In the phylogenetic scheme of Simone (2011), $H$. variabilis would certainly be placed in the "node U - Neritimorpha" (fig. 20), in having the main neritimorph synapomorphies, such as the absorption of the inner shell whorls, the pair of columellar muscles inserting directly on the columellar side of the aperture, and the calcareous operculum. The presence of well-developed pallial gonoducts, indicating internal fertilization and production of egg capsules, as shown in Figs. 23, 34 and 35, are one of the synapomorphies of the Adenogonogastropoda Simone, 2011, a taxon uniting Neritimorpha with the Apogastropoda. Other main characters are the eyes with a lens, loss of the right pallial structures (gill, osphradium, and hypobranchial gland), and loss of the right kidney. All features were confirmed in the species studied here.

The monotocardian condition of the Helicinidae, i.e., a single auricle in the heart, has been an interesting enigma (Little, 1972), as this character is shared with the higher gastropods. The basal neritimorphs, despite having lost the right pallial structures, still retain the left auricle (Estabrooks et al., 1999; Barroso et al., 2012). Taking into consideration the information provided by Simone (2011), the monotocardian condition of the helicinids is a remarkable convergence with the apogastropods (sensu Simone, 2011), also known as Monotocardia. However, a different situation was found by Uribe et al. (2016), using a molecular approach, in that the marine diotocardian neritids appeared as a more derivative taxon inside Neritimorpha, preceded by the representatives of the three terrestrial superfamilies Neritopsoidea, Hydrocenoidea, and Helicinoidea in their phylogram (Uribe et al., 2016: fig. 2). From a morphological point of view, this arrangement is not the most parsimonious, as the most derived taxon (Neritidae) supposedly would have reverted to the marine environment and recovered several morphological plesiomorphies, such as the bipectinate gill, the osphradium, and the right auricle. Possibly to resolve this dilemma, Uribe et al. (2016) suggested a non-parsimonious explanation, in which the three most basal superfamilies evolved independently from different marine ancestors.

\section{ACKNOWLEDGMENTS}

We are deeply grateful to José Coltro Jr. (Femorale) for providing the material studied here, and to Lara Guimarães (MZSP) for helping with the SEM examination. To Rodrigo B. Salvador for suggestions in an early phase of the paper. I also thank the editor and both anonymous referees for their suggestions and comments, and Janet Reid for English polishing. 


\section{REFERENCES}

Baker, H. 1922. Notes on the radula of the Helicinidae. Proceedings of the Academy of Natural Sciences of Philadelphia, 74: 29-67, pls. 3-7.

Baker, H. 1923. The Mollusca collected by the University of MichiganWilliamson Expedition in Venezuela. Occasional Papers of the Museum of Zoology. University of Michigan, 137: 1-59, pls. 1-5.

Baker, H. 1926. Anatomical Notes on American Helicinidae. Proceedings of the Academy of Natural Sciences of Philadelphia, 78: 34-56, pls. 5-8.

Barroso, C.X.; Matthews-Cascon, H. \& Simone, L.R.L. 2012. Anatomy of Neritina zebra from Guyana and Brazil (Mollusca, Gastropoda, Neritidae). Journal of Conchology, 41(1): 49-64.

Boss, K.J. \& Jacobson, M.K. 1974. Monograph of the genus Lucidella in Cuba (Prosobranchia: Helicinidae). Occasional Papers on Mollusks, 4(48): 1-27.

Bourne, G.C. 1911. Contributions to the morphology of the group Neritacea of the aspidobranch gastropods. Part II. The Helicinidae. Proceedings of the Zoological Society of London, 1911: 759-809, pls. 30-42.

Cowie, R.H.; Cazzaniga, N.J. \& Glaubrecht, M. 2004. The South American Mollusca of Johann Baptist Ritter von Spix and their publication by Johann Andreas Wagner. Nautilus, 118: 71-87.

Estabrooks, W.A.; Kay, E.A. \& McCarthy, S.A. 1999. Structure of the excretory system of Hawaiian nerites (Gastropoda: Neritoidea). Journal of Molluscan Studies, 65: 61-72.

Little, C. 1972. The evolution of kidney function in the Neritacea (Gastropoda, Prosobranchia). Journal of Experimental Biology, 56: 249-261.

Richling, I. 2004. Classification of the Helicinidae: review of morphological characteristics based on a revision of the Costa Rican species and application to the arrangement of the Central American mainland taxa (Mollusca: Gastropoda: Neritopsina). Malacologia, 45(2): 195-440.

Richling, I. 2009. The radiation of the Helicinidae in New Caledonia (Mollusca: Gastropoda: Neritopsina) including zoogeographical considerations. In: Grandcolas P. (Ed.). Zoologia Neocaledonica 7. Biodiversity studies in New Caledonia. Mémoires du Muséum National d'Histoire Naturelle, 198: 247-372.

Richling, I. 2014. Poorly explored jewels of the tropics - estimating diversity in non-pulmonate land snails of the family Helicinidae (Neritopsina). American Malacological Bulletin, 32(2): 246-258.
Richling, I. \& Bouchet, P. 2013. Extinct even before scientific recognition: a remarkable radiation of helicinid snails (Helicinidae) on the Gambier Islands, French Polynesia. Biodiversity and Conservation, 22: 2433-2468.

Richling, I. \& Glaubrecht, M. 2008. The types of Neotropical Helicinidae (Mollusca, Gastropoda, Neritopsina) in the Malacological Collection of the Museum für Naturkunde Berlin: an annotated catalogue, with emphasis on Cuban land snails. Zoosystematics and Evolution, 84(2): 265-310.

Salgado, N.C. \& Coelho, A.C.S. 2003. Moluscos terrestres do Brasil (gastrópodes operculados ou não, exclusive Veronicellidae, Milacidae e Limacidae). Revista de Biología Tropical, 51(suppl. 3): 149-189.

Simone, L.R.L. 2004. Comparative morphology and phylogeny of representatives of the superfamilies of architaenioglossans and the Annulariidae (Mollusca, Caenogastropoda). Arquivos do Museu Nacional, 62(4): 387-504

Simone, L.R.L. 2006. Land and freshwater mollusks of Brazil. São Paulo, EGB \& FAPESP. 390p

Simone, L.R.L. 2011. Phylogeny of the Caenogastropoda (Mollusca), based on comparative morphology. Arquivos de Zoologia, 42(4): 161-323.

Simone, L.R.L. \& Salvador, R.B. 2016. Taxonomical study on a sample of land snails from Nanuque (Minas Gerais, Brazil, with description of three new species. Stuttgarter Beiträge zur Naturkunde A, Neue Serie, 9: 9-30.

Uribe, J.E.; Colgan, D.; Castro, L.R.; Kano, Y. \& Zardoya, R. 2016. Phylogenetic relationships among superfamilies of Neritimorpha (Mollusca: Gastropoda). Molecular Phylogenetics and Evolution, 104: 21-31.

Wagner, A.J. 1906. Helicinenstudien, Monographie der Genera Palaeohelicina A.J. Wagner und Helicina Lamarck. Denkschriften der Österreichischen Akademie der Wissenschaften, Mathematisch-Naturwissenschaftliche Klasse, 78: 203-248.

Wagner, A.J. 1907-1911. Die Familie der Helicinidae. Neue Folge. In: Martini \& Chemnitz, Systematisches Conchylien-Cabinet. Bauer \& Raspe. Nürnberg, Verlag von Bauer \& Raspe. v. 1, pt. 18, p. 1-391, pls. 1-70.

Wagner, J.A. 1827. Testacea fluviatilia quae in itinere per Brasiliam annis MDCCCXVII-MDCCCXX. Monachii, Typs C. Wolf, Munich. 36p. 